\title{
World Englishes (WE) and English as Lingua Franca (ELF): Implications for English Teaching and Learning
}

\author{
Wei Leyi
}

\begin{abstract}
The worldwide use of English nowadays has promoted the development of WE and ELF, which have brought about certain challenges to traditional concepts of English education. Although with different interpretations based on various literature, in WE and ELF, both a variety of English around the world and effective communication in the language are thought highly of. In this sense, there are three measures that need to be taken. First, instead of sticking to native speaker model which merely values one variety of English, teachers should assist students achieving intelligibility among different speakers during interactions, promoting communicative approach and holding communicative activities in order to achieve the goal. Second, teaching methods and contents as well as assessment are supposed to correspond to needs of students, who probably learn English as a second or foreign language and use it for specific purpose only. Third, compared to native monolingual teachers of English, local bilingual teachers, who could perform better towards the two measures above due to characteristics such as local cultural insights, sympathy for students' learning problems and the ability to use first language for assistance of teaching, are probably more suitable for successful English teaching in some cases. In this essay, after characteristics of WE and ELF are synthesized, implications on English teaching and learning will be discussed. In conclusion, the target of intelligibility, contextualized teaching and the selection of local bilingual teachers with high proficiency, all of which result from influence of WE and ELF, should be promoted in English education.
\end{abstract}

Index Terms-WE, ELF, English education, intelligibility, contextualized teaching and learning, local bilingual teachers.

\section{INTRODUCTION}

With the popularity of English around the world in present days, the language has widely been used among speakers with different first languages for successful communication, functioning as a global lingua franca [1]. Due to its international use, different varieties of the language emerged and have promoted the development of WE [2], [3]. However WE gained very little attention while ELF has not yet existed in the field of Teaching English to Speakers of Other Languages (TESOL) three decades ago [4]. However, they have developed rapidly in recent years [4] and been researched by many scholars. As relatively new terms in the

Manuscript received December 14, 2019; revised March 16, 2020.

Wei Leyi is with the University of Hong Kong, Hong Kong (e-mail: wlycatherine@126.com). field, their emergence and development have challenged some traditional educational concepts, which has emphasized the target of achieving native speaker competence and having a good command of English cultures with native teachers highly preferred, and thus have considerable implications on English language teaching and learning.

The essay aims to explore implications of WE and ELT on English teaching and learning. The paper will first present different interpretations about WE and ELF respectively based on literature before common characteristics of the two terms are summarized. Then it will elaborate reasons why WE and ELF challenge some traditional concepts of English language education and how these concepts should be changed. It is believed that there are three aspects of English education which are supposed to be adjusted from the perspectives of WE and ELF. First, instead of sticking to native speaker model which merely regards one variety of English as the standard, teachers should assist students achieving intelligibility among different speakers during interactions, promoting communicative approach and holding communicative activities in order to achieve the target. Second, teaching methods and contents as well as assessment are supposed to correspond to needs of students, who probably learn English as a second or foreign language and use it for specific purpose only. Third, compared to native monolingual teachers of English, local bilingual teachers, who could perform better towards the two measures above due to characteristics such as local cultural insights, sympathy for students' learning problems and the ability to use first language for assistance of teaching, are probably more suitable for successful English teaching in some cases.

\section{DEFINITIONS OF WE AND ELF}

One of widely-accepted concepts related to WE is Kachru's [5] model, which divides communities where English is used into three circles according to status of the language. The Inner Circle refers to regions where English is used as a first language. The Outer Circle consists of communities that regard English as a second language, which also serves as one of the official languages while other communities using English as a foreign language are labeled the Expanding Circle. Based on this three-circle model, as Bolton [2] suggested, there are three common definitions of the term WE. The first one refers to all varieties of English in the world regardless of status of the language. The second one is in a narrower sense, containing new varieties of English in the Outer Circle such as those in Kenya, India and Singapore. The third definition is termed "Kachruvian 
approach (p. 367)", emphasizing "inclusivity and pluricentricity (p. 367)" of English language. In this sense, all varieties of English are respected equally [6] and there is no one being regarded superior. Although there are a range of interpretations of WE, the existence of different varieties and norms of English around the world is admitted.

In terms of ELF, there are also different definitions of it. House (as cited in [6]) pointed out that it is applied among speakers whose first language is not English. This means speakers from the Inner Circle are excluded. However, according to Seidlhofer [1] and Jenkins [7], ELF refers to the phenomenon that English is used as a common choice in interactions among speakers with different first languages. In this sense, all speakers from the three circles are included as most ELF researchers believe [7] although in a majority of cases, the interactions take place among non-native English speakers [1], [7]. Despite differences of speakers involved between these two definitions, they both refer to the fact that when speakers with different linguistic background interact with each other, they select English as the language for successful communication. Therefore, no matter where the speakers come from, the goal for ELF is to interact successfully in communities. Speakers need to adjust to varieties of English they are involved in [3], [4], [6]-[8] to communicate with specific interlocutors effectively and successfully.

By definition, it seems that WE and ELF have different meanings. The former one emphasizes existence and usage of various norms of English around the world while the latter focuses on interactions among speakers using English [6]. However, they are closely relevant and connected since the need to make adjustment for successful interactions from the perspective of ELF already includes admission of varieties of English. With both their focuses on values of different varieties of English, these two relatively new terms bring out challenges on some traditional concepts, which need to be changed to facilitate English education from their perspectives.

\section{IMPLICATIONS OF WE AND ELF ON ENGLISH TEACHING AND LEARNING}

\section{A. The Goal of Intelligibility}

Traditionally, English of native speakers especially American and British one is regarded as the sole model and standard for students, who are required to achieve native speaker competence, which serves as the principal goal for language education, and any other varieties of English are regarded as obstacles for successful English learning [8], [9]. However, there are oppositions against the use of this model. As Kirkpatrick [8] pointed out, it is demanding for many learners, especially those from the Expanding Circle to achieve the native-speaker proficiency. Thus, it is likely that the goal remains unachievable and students feel de-motivated towards English learning [8]. Also, teachers' confidence and joy of English teaching can be negatively affected by the unachievable goal.

In addition, from the perspectives of WE and ELF which emphasize different varieties of English and effective interactions, intelligibility is the goal for English use [10], [11]. According to Kirkpatrick [12], there are increasingly more non-native English speakers around the world, who are able to achieve intelligibility and even more intelligible than native speakers. Also, use of some forms, which are different from those of native speakers, for example, the absence of third person singular tense following verbs frequently used by speakers from Outer Circle [1], do not cause communication breakdown. Therefore, probably it is not imperative to sound like native speakers. Moreover, certain variety of English such as the American or British one should not be seen as the sole Standard English, which was defined by a number of researchers. Quirk (as cited in [13]) regarded it as English which is commonly accepted and Greenbaum (as cited in [14]) emphasized its feature of prestige because of acceptance by the educated. Peters [15] suggested that it does not refer to one certain dialect. Although there are various interpretations of Standard English, the common ground is that it is not only one certain variety. Therefore, it appears that it is unnecessary to insist on the native speaker model for English teaching and learning.

Another important aspect for WE and ELF is that speakers need to make adjustments to different interlocutors including those from not only the Inner Circle but also the Outer and Expanding Circles for effective interactions [3], [4], [6]-[8]. Thus, it is not enough for students to merely master native speaker model, which in most cases is of little relevance to non-native English communities, interactions in which are the most common in ELF context [1], [7]. Therefore, it seems that it is also unreasonable to merely adopt the native speaker model. Instead, abilities to achieve intelligibility in interactions and "negotiate the varieties ([16] p. 233)" in different circles of communities need to be developed. In order to achieve these, it is necessary to engage students in communicative activities, where they are trained for effective meaning negotiation rather than regard native-speaker competence as the goal. Additionally, students should be exposed to various varieties of English. According to Jenkins [7], there are two kinds of English for effective interactions. "Common ground (p. 201)" refers to knowledge shared by a majority of speakers while "local variation (p. 201)" is applied in specific communities. Thus, not only should commonly applied knowledge be taught to students, but different varieties are also needed for better pragmatic use in real life.

\section{B. Contextualized Teaching and Learning}

According to McKay [17], due to the spread of English around the world, there are a great number of "bilingual users of English (p. 33)", who learn the language as an addition to their mother tongue. The emergence and development of the users are closely related to ELF. With English serving as a common language choice for interactions, increasingly more people select to learn English, and this in turn maintains and raises the status of ELF [17]. The users, by definition, are not those from the Inner Circle applying English as their first language and using it in everyday life. Instead, they only use the language in specific circumstances for specific purpose 
[17] and interactions among these users account for great proportions around the world [1], [7], [17]. From the perspectives of WE and ELF, achieve intelligibility in communities is the target for language use [10], [11], and therefore the most relevant goal for the bilingual users is to be intelligible in specific communities they are involved in. Therefore, it is of vital importance for the users to develop "the ability to use the English language effectively for specific purposes, functions, and discourses in specific communities ([16] p. 235)". In other words, they are supposed to be taught and master varieties and norms that are most relevant to them according to their needs.

As Jenkins [18] proposed, in order to achieve intelligibility, some core phonological features, which are crucial for intelligibility in ELF interactions, should be adopted as essence of teaching. For example, she [19] found that a Korean speaker's mispronunciation of the sound /f/, which was defined as a core feature in English, leads to confusion of his interlocutors, who cannot understand what he means. Apart from the core features, there is also non-core ones which do not cause communication problems and thus are not important for teaching and learning [18]. However, according to Alqahtani [20], for Arabic speakers of English, under the influence of their first language, communication problems are likely to emerge because of some non-core features which are recognized by other communities. Thus, the differences and division of core and non-core features are not fixed but need to be considered carefully. In this sense, the teaching contents, including selection of norms and linguistic features, need to be contextualized according to learners' needs.

Apart from the teaching contents, assessment is also supposed to be contextualized [16]. Validity is of vital importance for assessment [21]. To achieve validity, assessment should be designed to measure what is proposed to be measured, what has been taught and what is supposed to be achieved [9]. It is likely to be unreasonable to assess knowledge that students have never learned. Since the teaching contents are decided based on specific contexts and students' needs, assessment should be designed in the same way, reflecting key features of knowledge taught so that the results can facilitate students' further study [9]. Moreover, the goals of effective interactions in different circumstances should also be reflected in assessment. Therefore, performance-based assessment, where students' abilities are performed and measured in specific real-life situations [22], should be adopted [16]. By creating specific contexts where students actually apply English, their ability of achieving intelligibility can be evaluated more effectively.

\section{The Choice of Local Bilingual Teachers}

Traditionally, it is native speaker teachers that are often responsible for students' learning, deciding most of the teaching contents and methods [9]. However, from the perspectives of WE and ELF, it is likely that local bilingual teachers are more appropriate to take the position. One of the important reasons for choosing native speaker teachers is that they are equipped with native speaker competence, which is supposed to be transmitted to students so that they can have the same competence after taught by native teachers [23]. However, language competence is not the only variable influencing effectiveness of teaching [23]. Teachers with merely native speaker competence are unlikely to ensure students' high language proficiency. More importantly, this reason is based on the target of gaining native speaker competence, which, from the perspectives of WE and ELF, is inappropriate to a large extent.

Another reason for the choice is that students have been traditionally expected to master English cultures, such as American and British ones [12], which English native speaker teachers are more likely to have deep understanding of. However, under the circumstances of WE and ELF, the goal for English language learning is to use it effectively in specific communities that they are relevant to instead of having native speaker competence and mastering English cultures. For the bilingual users, mostly they interact with people with similar linguistic background [1], [7]. In this case, these users tend to share information about their own communities including cultures to their interlocutors [11], [12], [17], and thus the English cultures could be of little relevance to the users [12]. What they need to master is local cultures instead of the English ones [11], [12]. Local bilingual teachers who are more familiar with local situations are able to provide rich information including the local cultural insights for students and assist them better understanding it [12]. In addition, in order to achieve intelligibility in different relevant settings, it is necessary to develop students' "intercultural competence ([12], p. 28)" to facilitate various interactions in different communities.

Moreover, there are a number of advantages of local bilingual teachers. First, they have more empathy for students since they have ever learned the language in similar situations [23]. Thus, they are more sensitive and aware of students' difficulties and needs of language learning, and are more able to help students address them with appropriate strategies and methods, which have proven to be effective during their own study [23]. Second, the teachers can act as models for students' learning as successful second or foreign language learners because they develop language proficiency effectively in similar background and condition [23]. Native speaker teachers who have never been bilingual learners of the language are less likely to be ideal models for students [23] and probably have less empathy for students than the local bilingual ones. Third, local bilingual teachers can use their first language to assist students' learning [12], [23]. Littlewood and $\mathrm{Yu}[24]$ advocated first language use during language teaching. They believed that first language can be used for some purpose such as providing scaffolding, maintaining classroom order, clarifying rules for activities and ensuring understanding, which are beneficial for language learning especially for low-proficient students. Therefore, it is local bilingual teachers with intercultural competence and high proficiency that are actually needed rather than native speaker teachers in some cases.

\section{CONCLUSION}

With WE and ELF developing quickly as popular new 
terms in the field of English language teaching and learning, a great number of researchers and scholars have studied them thoroughly and proposed various definitions. Based on the three-circle model by Karachu [5], three different interpretations of WE are presented in this essay with the common ground of admission of different varieties of English around the world. In terms of ELF, regardless of disagreement of speakers involved, it refers to English as the language used among speakers with multilingual background for effective interactions. In these senses, they have brought challenges to some traditional educational concepts and provided new insights in English education. First, WE and ELF have challenged the native speaker model, which is insufficient and unachievable for most language learners due to various varieties of English emerged and developed worldwide. For effective communication, speakers need to make adjustments to different varieties of the language instead of insisting on one type. In this sense, it is the achievement of intelligibility that ought to be the goal for English language teaching and learning rather than the traditional native speaker competence. To achieve the goal, communicative activities are supposed to be adopted with exposure to various varieties of English. Second, in most cases, traditional curriculums are greatly influenced by the Inner Circle with English cultures regarded as the only imperative learning contents. However, from the perspectives of WE and ELF, this also needs to be changed. Closely connected with ELF, bilingual English language users have grown rapidly around the world and they tend to apply the language for specific purpose in specific contexts, mostly beyond the Inner Circle. It is necessary for them to master what is most relevant to them and thus teaching contents and assessment need to be contextualized. Third, due to the inappropriateness of native speaker model, local bilingual teachers rather than native speaker ones are likely to be better choice for English language education. These local teachers with high English competence are probably more able to provide local cultural insights, which are greatly needed for many learners. Also, there are other advantages for local bilingual teachers including empathy for students' learning difficulties, models set as successful second or foreign language learners and ability to use learners' first language in order to assist English learning, which native speakers are difficult to achieve.

In conclusion, developing quickly in recent times, WE and ELF has challenged traditional concepts and offered new insights in the field of English teaching and learning including the goal of intelligibility, the need to contextualize teaching contents and assessment and choice of local bilingual teachers with high English proficiency. Educational departments, educators and teachers are supposed to take these factors into consideration and take proper actions to facilitate English education. First, students and teachers should be encouraged to regard intelligibility as the target of English education rather than merely stick on native speaker competence, engaging themselves more in communicative approaches. Second, instead of having uniform assessment, different groups of students are supposed to be evaluated differently with the contents and methods changed constantly according to their specific needs. Third, local bilingual teachers with high competence and proficiency should be equally thought highly of since they could be able to have more positive effect on teaching and learning than native teachers in some cases. They are supposed to make good use of their own advantages to assist students' English learning.

\section{CONFLICT OF INTEREST}

The authors declare no conflict of interest.

\section{AUTHOR CONTRIBUTIONS}

Wei Leyi conducted the literature review, wrote the paper and had approved the final version.

\section{REFERENCES}

[1] B. Seidlhofer, "English as a lingua franca," ELT Journal, vol. 59, no. 4, pp. 339-341, 2005. doi:10.1093/elt/cci064

[2] K. Bolton., "World Englishes," Handbook of Applied Linguistics, Oxford, England: Blackwell, 2004, pp. 367-396.

[3] A. Cogo, "English as a lingua franca: concepts, use, and implications," ELT Journal, vol. 66, no. 1, pp. 97-105, 2012.

[4] J. Jenkins, "Current perspectives on teaching World Englishes and English as a lingua franca," TESOL Quarterly, vol. 40, no. 1, pp. 157-181, 2006. doi:10.2307/4026451

[5] B. B. Kachru, "Standards, codification and sociolinguistic realism: the English language in the outer circle," English in the World: Teaching and Learning the Language and Literatures, Cambridge: Cambridge University Press, 1985, pp. 11-30.

[6] S. L. McKay, "English as an International language: What it is and what it means for pedagogy," RELC Journal: A Journal of Language Teaching and Research, vol. 49, no. 1, pp. 9-23, 2018.

[7] J. Jenkins, "English as a lingua franca: Interpretations and attitudes," World Englishes, vol. 28, no. 3, pp. 200-207, 2009.

[8] A. Kirkpatrick, "Setting attainable and appropriate English language targets in multilingual settings: A case for Hong Kong," International Journal of Applied Linguistics, vol. 17, no. 3, pp. 376-391, 2007.

[9] J. D. Brown, "EIL curriculum development," Principles and Practices for Teaching English as an International Language, Taylor and Francis, 2012, pp. 147-167.

[10] A. Davies, "Does language testing need the native speaker?" Language Assessment Quarterly, vol. 8, no. 3, pp. 291-308, 2011, doi:10.1080/15434303.2011.570827.

[11] A. Kirkpatrick, "English as an Asian lingua franca: The 'lingua franca approach' and implications for language education policy," Journal of English as a Lingua Franca, vol. 1, no. 1, pp. 121-139, 2012.

[12] A. Kirkpatrick, "Teaching English in Asia in non-Anglo cultural contexts: Principles of the lingua franca approach," English Language Education, vol. 1, pp. 23-34, 2014.

[13] A. Davies, "Standard English: Discordant voices," World Englishes, vol. 18, no. 2, pp. 171-186, 1999, doi:10.1111/1467-971X.00132.

[14] M. A. K. Halliday, "Written language, standard language, global language," World Englishes, vol. 22, no. 4, pp. 405-418, 2003 , doi:10.1111/j.1467-971X.2003.00309.x.

[15] P. Peters, The Cambridge Guide to Australian English Usage, 2nd ed, United Kingdom: Cambridge University Press, 2007.

[16] S. Canagarajah, "Changing communicative needs, revised assessment objectives: Testing English as an International language," Language Assessment Quarterly, vol. 3, no. 3, pp. 229-242, 2006, doi:10.1207/s15434311laq0303_1.

[17] S. L. McKay, "EIL curriculum development," RELC Journal, vol. 34, no. 1, pp. 31-47, 2003.

[18] J. Jenkins, English as a Lingua Franca: Attitudes and Identity, Oxford: Oxford University Press, 2007.

[19] J. Jenkins, "A sociolinguistically based, empirically researched pronunciation syllabus for English as an International language," Applied Linguistics, vol. 23, no. 1, pp. 83-103, 2002 , doi:10.1093/applin/23.1.83.

[20] M. Alqahtani, "Native speakers model or English as lingua franca core? An exploratory study investigating both issues in Arabic-speaking classrooms of English," Arab World English Journal, vol. 4, no. 1, pp. 135-143, 2001

[21] G. Stobart, "Valid assessment," Assessment in Education: Principles, Policy \& Practice, vol. 13, no. 1, pp. 1-3, 2006. 
[22] E. F. Prastikawati, "EFL learners' responses on the use of performance-based assessment," Lensa: Kajian Kebahasaan, vol. 8, no. 1, pp. 75-86, 2018, doi:10.26714/lensa.8.1.2018.75-86.

[23] P. Medgyes, "Native or non-native: Who's worth more?" ELT Journal, vol. 46, no. 4, pp. 340-349, 1992.

[24] W. Littlewood and B. Yu, "First language and target language in the foreign language classroom," Lang. Teach., vol. 44, p.1, pp. 64-77, 2011, doi:10.1017/S0261444809990310.

Copyright $\odot 2020$ by the authors. This is an open access article distributed under the Creative Commons Attribution License which permits unrestricted use, distribution, and reproduction in any medium, provided the original work is properly cited (CC BY 4.0).

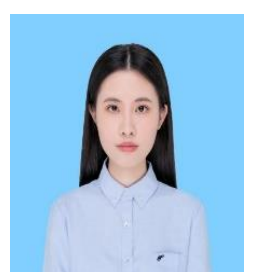

Wei Leyi was born in Guangdong province, China and received a bachelor's degree in English language and literature from Shenzhen University in 2018, and is now a master majoring in TESOL in the University of Hong Kong. She used to be a part-time teaching assistant in Shenzhen University and has taught IELTS in Shantou. She is now an admitted instructor in Shantou University. Her research interests are English language education and second language acquisition. 